\title{
JoyaPhos: An Atropisomeric Teraryl Monophosphine Ligand
}

\author{
Alessandro Castrogiovanni, Dominik Lotter, Fabian R. Bissegger and Christof Sparr*
}

\author{
A. Castrogiovanni, Dr. D. Lotter, F. R. Bissegger, Prof. Dr. C. Sparr \\ Department of Chemistry \\ University of Basel \\ St. Johanns-Ring 19, 4056 Basel (Switzerland) \\ E-mail: christof.sparr@unibas.ch
}

for the formation of $\mathrm{N}$-arylindolines and a Pd-catalyzed asymmetric allylic alkylation (AAA), the latter serving to benchmark the ligands' capability to control stereocenter configuration using palladium catalysis. The synthesis of JoyaPhos ligands was envisaged by employing a de novo construction of the naphthalene core, followed by the installation of the side anthracenyl substituent, and a modular installation of phosphine moieties with distinct properties (Figure 1a). We thereby envisioned that the introduction of an all-carbon aromatic shielding group would differentiate JoyaPhos from commonly used chiral biaryl monophosphines, where oxygen or nitrogen substituents typically impact the electronic and steric properties of the ligand (Figure 1b).

\section{Introduction}

A crucial requirement for ligands suitable for stereoselective, catalyst-controlled processes, is to organize the reactants within the coordination sphere of the metal in a spatially well-defined environment. An attractive but challenging setting is represented by $\mathrm{Au}(\mathrm{I})$ catalysts, whose linear coordination places the substrate opposite to the ancillary ligand, rendering enantioinduction particularly demanding. ${ }^{[1]}$ Since the discovery of BINAP, atropisomeric binaphthyl bis- and monophosphines with their remarkably suitable topology, have become privileged scaffolds as supporting ligands in homogeneous catalysis, both in industry and academia. ${ }^{[2-4]}$ While commonly obtained from inexpensive BINOL and successfully utilized in a vast number of transition metal catalyzed transformations, the binaphthyl core also presents several limitations when further tunability is required. ${ }^{[5]}$ Higher structural variability is often achieved at the cost of tedious functionalizations, especially when accessing monophosphines with a binaphthyl skeleton as a core motif. Monodentate phosphorous ligands differ from their bidentate counterparts in many aspects, particularly as they allow the metal center to be coordinatively unsaturated in order to catalyze reactions that would otherwise be unfavored. ${ }^{[6-9]}$ Methods for the de novo synthesis of monophosphines with increased structural variability are therefore highly desirable, particularly if a compact ligand design becomes feasible by straightforward and operationally simple synthetic approaches.

Based on our earlier work on the stereoselective construction of aromatic structures by catalytic aldol condensation reactions, ${ }^{[10]}$ we thus synthesized atropisomeric teraryl ligands featuring a rotationally restricted ortho-substituted phenyl-naphthylanthracenyl scaffold, which we named JoyaPhos. Their activity and selectivity were evaluated by gold(I)-catalyzed enyne cycloisomerization and [2+2] cycloaddition of a terminal alkyne using methylstyrene. The atropisomeric ligands were also assessed in an atroposelective Pd-catalyzed C-N cross-coupling

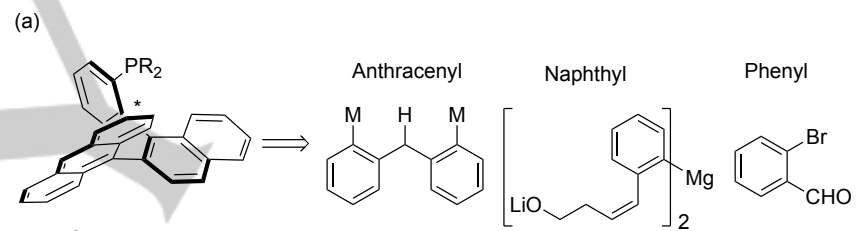

$\left(S_{a}\right)-R_{2}$ JoyaPhos

(b)
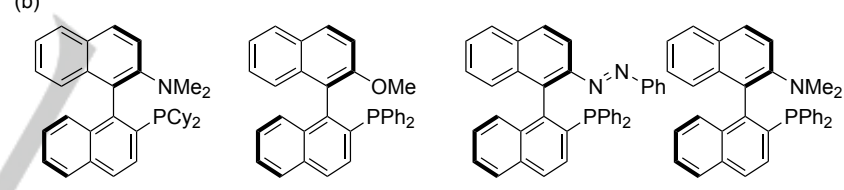

$\left(R_{\mathrm{a}}\right)$-KenPhos

$\left(R_{\mathrm{a}}\right)-\mathrm{MOP}$

$\left(R_{\mathrm{a}}\right)-\mathrm{AZOP}$

$\left(R_{\mathrm{a}}\right)$-MAP

Figure 1. (a) Synthetic approach for JoyaPhos ligands by the de novo construction of the naphthyl backbone by a stereoselective aldol condensation. (b) Atropisomeric binaphthyl monophosphines commonly feature an oxygen- or nitrogen-containing functionality at the 2'-naphthyl position.

\section{Results and Discussion}

The synthesis of the ligands began with the addition of metalated building block $2^{[10 \mathrm{~b}, 10 \mathrm{c}]}$ to 2-bromobenzaldehyde $\mathbf{1}$, affording the corresponding diol ( \pm )-3 in $69 \%$ yield (Scheme 1). An ensuing double oxidation with IBX yields the ketoaldehyde intermediate, which is a suitable starting material for the stereoselective aldol addition that occurs in presence of tetrazole-derived catalyst 4 . A subsequent arene-formation is readily achieved by treatment with intermediate. The aldehyde functionality was next converted to a carboxylic acid by a Lindgren-Kraus oxidation and a subsequent esterification at $80^{\circ} \mathrm{C}(16 \mathrm{~h})$ delivered the corresponding methyl ester $\mathbf{5}$ in $80 \%$ overall yield over five expeditious steps. Amberlite IRA-96, yielding the atropisomeric naphthaldehyde 

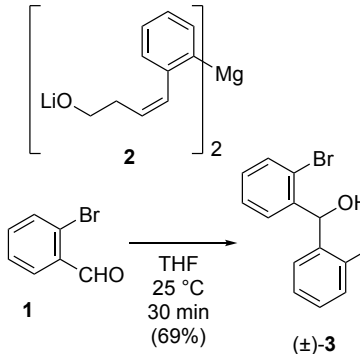

i) $\mathrm{IBX}, \mathrm{CH}_{3} \mathrm{CN}, 50^{\circ} \mathrm{C}, 16 \mathrm{~h}$ ii ) $(S) \mathrm{N}^{(\mathrm{N})}$

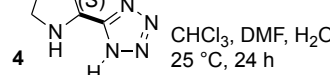

iii ) Amberlite IRA-96, $\mathrm{CHCl}_{3}, 25^{\circ} \mathrm{C}, 3 \mathrm{~h}$

iv ) $\mathrm{NaClO}_{2}, \mathrm{NaH}_{2} \mathrm{PO}_{4} \cdot 4 \mathrm{H}_{2} \mathrm{O}$,

2-methyl-2-butene, $\mathrm{H}_{2} \mathrm{O}$, THF

$t-\mathrm{BuOH}, 25^{\circ} \mathrm{C}, 16 \mathrm{~h}$

v) $\mathrm{MeOH}, \mathrm{H}_{2} \mathrm{SO}_{4}, 80^{\circ} \mathrm{C}, 16 \mathrm{~h}$

( $80 \%$ yield over 5 steps)
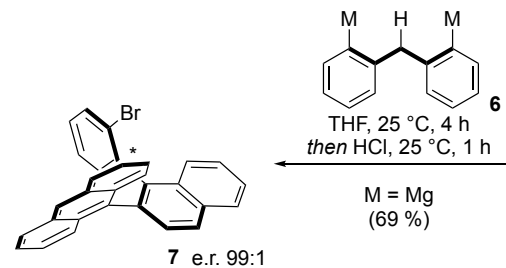

$M=M g$

$(69 \%)$

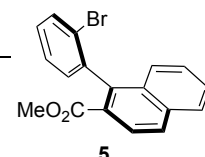

Scheme 1. Synthesis of the ligand backbone via a stereoselective aldo condensation and direct ester-to-arene transformation from inexpensive 2-bromobenzaldehyde.

With the ester functionality established on the naphthalene moiety, we employed a methodology developed in our group for the direct conversion of esters to arenes. ${ }^{[11]}$ The introduction of the anthracenyl functionality by using the corresponding bifunctional organomagnesium reagent 6 thereby represents a chain termination strategy for the oligo-1,2-arylene synthesis, ${ }^{[10 b]}$ which smoothly delivers the halogenated intermediate 7 in $69 \%$ yield with 99:1 enantiomeric purity. The obtained anthracenylnaphthyl-phenyl bromide 7 suitably serves as precursor for the atropisomeric monodentate diarylteraryl- and dialkylterarylphosphines with different steric and electronic properties. Halogen-metal exchange of the brominated substrate, followed by treatment of the lithiated species with the corresponding chlorophosphine, hence delivered the teraryl phosphines 8, 9 and 10 as white solids after crystallization from $\mathrm{MeOH}$ in satisfactory yields (Scheme 2).
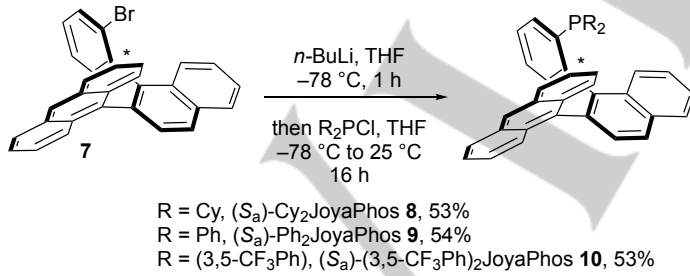

$\mathrm{R}=\mathrm{Cy},\left(\mathrm{S}_{\mathrm{a}}\right)-\mathrm{Cy}_{2} \mathrm{~J}$ JoyaPhos $8,53 \%$

$\mathrm{R}=\mathrm{Ph},\left(\mathrm{S}_{\mathrm{a}}\right)-\mathrm{Ph}_{2}$ JoyaPhos 9,54

$\mathrm{R}=\left(3,5-\mathrm{CF}_{3} \mathrm{Ph}\right),\left(\mathrm{S}_{\mathrm{a}}\right)-\left(3,5-\mathrm{CF}_{3} \mathrm{Ph}\right)_{2}$ JoyaPhos $10,53 \%$

Scheme 2. Divergent installation of different phosphine moieties via halogenmetal exchange and nucleophilic addition to the corresponding chlorophosphine.

X-Ray analyses of 8 and 9 (Figure 2) highlight the structurally defined scaffold of JoyaPhos with the sterically protected phosphine moiety, providing sufficient inertness towards molecular oxygen. ${ }^{[12]}$ The ligands can therefore be handled and stored on the bench at ambient temperature over extended periods of time without the need of inert conditions.
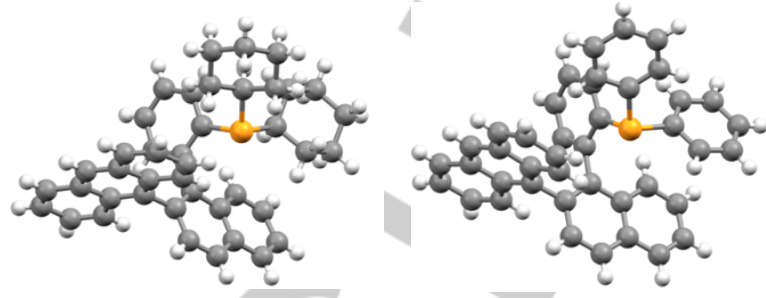

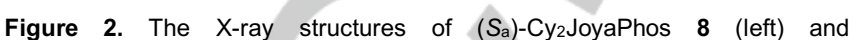
$\left(S_{a}\right)-P_{2}$ JoyaPhos 9 (right) highlight the $\mathrm{P}$ atom orienting the lone pair into the pocket defined by the scaffold, preventing oxidation by atmospheric oxygen. $( \pm)-8$ was utilized to obtain single crystals suitable for X-ray crystallographic analysis (structure of $\left(R_{\mathrm{a}}\right)-\mathbf{8}$ is omitted for clarity).

Given the topological features of JoyaPhos, we hypothesized that its well-defined structure and configurational stability might be suitable to accommodate the linear coordinating gold(I), creating the appropriate ligand environment for enantioselective catalysis. $\left(S_{a}\right)-P_{2}$ JoyaPhos and $\left(S_{a}\right)-\mathrm{Cy}_{2}$ JoyaPhos were consequently treated with $\mathrm{Me}_{2} \mathrm{SAuCl}$ in $\mathrm{CH}_{2} \mathrm{Cl}_{2}$ at $25^{\circ} \mathrm{C}$ for 30 minutes to obtain the corresponding $\mathrm{Au}(\mathrm{I})$ complexes in quantitative yields (Scheme 3 , top). Gratifyingly, the X-ray crystallographic analysis of $\left(S_{\mathrm{a}}\right)-\mathrm{Ph}_{2}$ JoyaPhosAuCl 11 confirmed the short distances between the gold center and the naphthyl face as well as the anthracenyl edge (Scheme 3, bottom left). ${ }^{[1]}$ With a P-Au bond length of 2.24 $\AA$ and as highlighted by the steric map ${ }^{[13]}$ (Scheme 3, bottom right), the substituents on the phosphorous provide hindrance on the upper part of the scaffold, whereas the naphthyl and anthracenyl moiety shield the back and lateral part of the metal center. Overall, a sterically demanding ligand, with a differentiated quadrant occupation and a buried volume of $52 \%$ was observed for $\left(S_{a}\right)-P_{2}$ JoyaPhos 11, providing a ligand distinct from previous structures. ${ }^{[14]}$ The activity and selectivity of the newly formed gold complexes were next tested by the [2+2] cycloaddition of phenylacetylene 13 with $\alpha$-methylstyrene 14 and the cycloisomerization of enyne 16 (Scheme 4). After generating
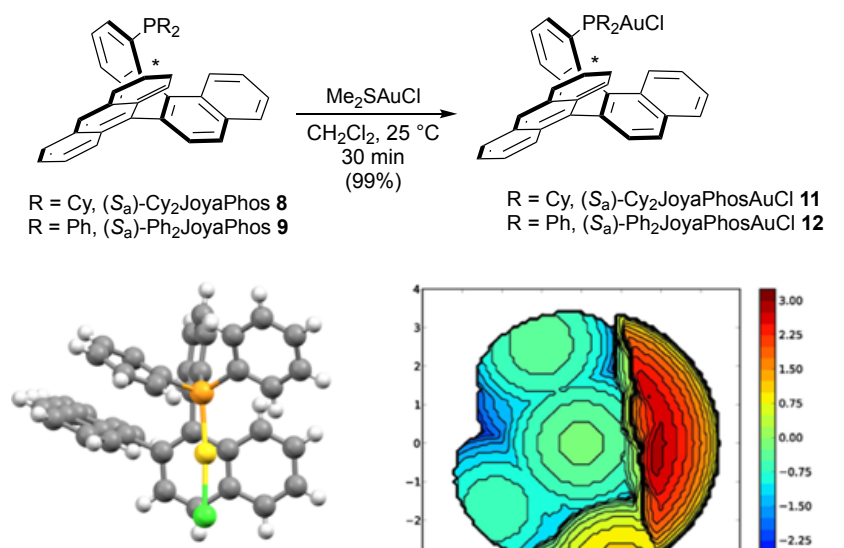

12

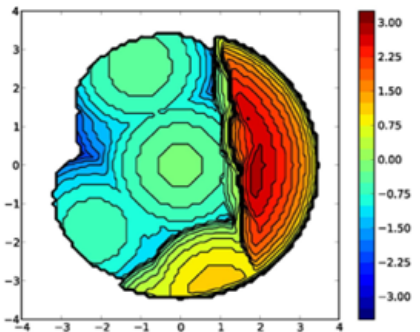

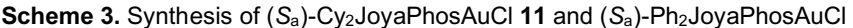
12 (top). As shown by the X-Ray structure of $\left(S_{a}\right)-P_{2}$ JoyaPhosAuCl 12 (bottom left), the Au atom is accommodated in a well-defined ligand structure. The steric profile corresponds to a buried volume of $52 \%$ (bottom right). ${ }^{[13]}$ 
active cationic $\mathrm{Au}(\mathrm{I})$ catalysts with $\mathrm{AgSbF}_{6},\left(\mathrm{~S}_{\mathrm{a}}\right)-\mathrm{Cy}_{2} \mathrm{~J}_{\text {JoyaPhos- }}$ $\mathrm{AuCl} 11$ provided the corresponding cyclobutene 15 in $51 \%$ yield and 56:44 e.r., whereas $\left(S_{\mathrm{a}}\right)-\mathrm{Ph}_{2}$ JoyaPhosAuCl 12 delivered the cycloaddition product in slightly higher yield and selectivity $(63 \%$ yield, 60:40 e.r.). Interestingly, $\left(S_{a}\right)$-Ph2JoyaPhos 12 provided a markedly improved yield in the cycloisomerization of enyne 16, delivering the cycloisomerization product 17 in 66:34 e.r. (90\% yield), whereas $\left(S_{\mathrm{a}}\right)-\mathrm{Cy}_{2}$ JoyaPhos 11 gave only $12 \%$ of the desired product with an e.r. of 51:49. The observed selectivity trends therefore suggest that the smaller steric bulk of the phenyl groups of $\left(S_{a}\right)-P_{2}$ JoyaPhos 12 might reduce both the front and back strain, ${ }^{[15]}$ whereas the cyclohexyl substituents could lead to an elongated $\mathrm{P}-\mathrm{Au}$ bond of the linear complex, placing the reactants farther away from the environment, thus affecting stereoinduction. Therefore, further functionalization of the backbone towards the incoming substrates, together with the suitable choice of phosphine substituents, might improve the stereoselectivity for gold-catalyzed processes ${ }^{[1]}$ using JoyaPhos ligands. (a)<smiles>C#Cc1ccccc1</smiles>
13

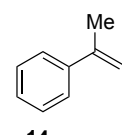

14

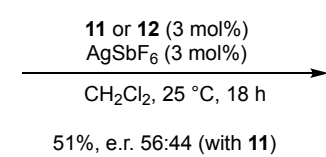

$51 \%$, e.r. $56: 44$ (with 11 )
$63 \%$, e.r. $60: 40$ (with 12)

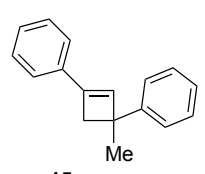

15 (b)
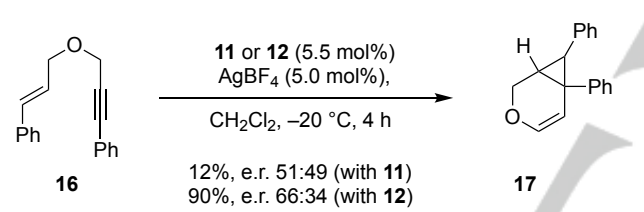

Scheme 4. (a) Gold(I)-catalyzed [2+2] cycloaddition of phenylacetylene 13 with methylstyrene 14. (b) Gold(I)-catalyzed cycloisomerization of enyne 16.
19 with a conversion of $40 \%$ after $16 \mathrm{~h}$ and an enantiomeric ratio of $56: 44$ (Table 1 , entry 1 ). The activity and selectivity of $\left(S_{a}\right)$ Cy $\mathrm{J}_{2}$ JoyaPhos 8 were next compared to Josiphos SL-J003-1 (Entry 2, 40\%, 47:53 e.r.) and SL-J009-1 (Entry 3, 10\%, 50:50 e.r.). A conversion of $10 \%$ and an e.r. of $52: 48$ was observed with the monodentate binaphthyl phosphine $\left(R_{\mathrm{a}}\right)$-MOP (Entry 4$)$ and with $\left(S_{\mathrm{a}}\right)$-SEGPHOS, no conversion could be detected (Entry 5). After optimization of the reaction conditions, $\left(S_{a}\right)-\mathrm{Cy}_{2}$ JoyaPhos 8 delivered the atropisomeric indoline in $82 \%$ isolated yield, with an increased e.r. of 65:35 (Entry 6). Employing $\left(S_{\mathrm{a}}\right)$ - $\mathrm{Ph}_{2}$ JoyaPhos 9 was inconsequential for the selectivity (Entry 7 ) but interestingly, an inverted sense of enantioselectivity was found with the fluorinated $\left(\mathrm{S}_{\mathrm{a}}\right)-\left(3,5-\mathrm{CF}_{3} \mathrm{Ph}\right)_{2}$ JoyaPhos 10 (Entry 8). In order to exclude the possibility of racemization over the course of the reaction, an enantiomerically pure sample of 19 was heated in THF for $16 \mathrm{~h}$ at $100{ }^{\circ} \mathrm{C}$. As the enantioenrichment was not impacted indicates that the $\mathrm{N}$-arylindoline $\mathbf{1 9}$ is configurationally stable under the reaction conditions.

Table 1. Atroposelective synthesis of $\mathrm{N}$-arylindolines via Pd-catalyzed $\mathrm{C}-\mathrm{N}$ cross-coupling using ligands $\mathbf{8 ,} 9$ and 10.
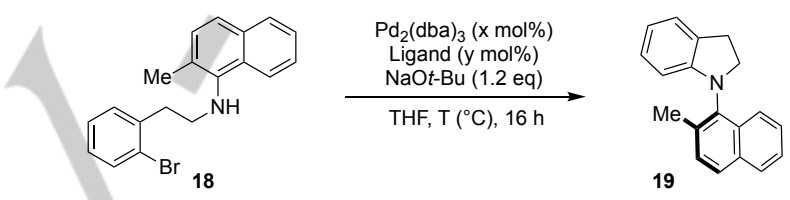

\begin{tabular}{|c|c|c|c|c|c|}
\hline Entry & $\begin{array}{c}\mathrm{Pd}_{2}(\mathrm{dba})_{3} \\
(\mathrm{~mol} \%)\end{array}$ & Ligand & $\mathrm{T}\left({ }^{\circ} \mathrm{C}\right)$ & Conversion \% & e.r..$^{[a]}$ \\
\hline 1 & 1 & $\begin{array}{c}8 \\
(3 \mathrm{~mol} \%)\end{array}$ & 85 & 40 & $56: 44$ \\
\hline 2 & 1 & $\begin{array}{l}\text { Josiphos } \\
\text { SL-J003-1 } \\
(3 \mathrm{~mol} \%)\end{array}$ & 85 & 40 & $47: 53$ \\
\hline 3 & 1 & $\begin{array}{l}\text { Josiphos } \\
\text { SL-J009-1 } \\
(3 \mathrm{~mol} \%)\end{array}$ & 85 & 10 & $50: 50$ \\
\hline 4 & 1 & $\begin{array}{c}\left(R_{\mathrm{a}}\right)-\mathrm{MOP} \\
(3 \mathrm{~mol} \%)\end{array}$ & 85 & 10 & $52: 48$ \\
\hline 5 & 1 & $\begin{array}{c}\left(S_{a}\right)- \\
\text { SEGPHOS } \\
(3 \mathrm{~mol} \%)\end{array}$ & 85 & $<1$ & - \\
\hline 6 & 2.5 & $\begin{array}{c}\mathbf{8} \\
(12 \mathrm{~mol} \%)\end{array}$ & 45 & $82^{[b]}$ & $65: 35$ \\
\hline 7 & 2.5 & $\begin{array}{c}\mathbf{9} \\
(12 \mathrm{~mol} \%)\end{array}$ & 45 & 99 & $65: 35$ \\
\hline 8 & 2.5 & $\begin{array}{c}10 \\
(12 \mathrm{~mol} \%)\end{array}$ & 45 & 99 & $35: 65$ \\
\hline
\end{tabular}

[a] The enantiomeric ratios were determined using a Chiralcel OJ-H column $\left(1.0 \mathrm{mLmin}^{-1}, n\right.$-heptane: $\left.i-\mathrm{PrOH}=90: 10\right) . \mathrm{t}_{\mathrm{R} 1}=7.0 \mathrm{~min}$ and $\mathrm{t}_{\mathrm{R} 2}=12.0 \mathrm{~min}$. [b] Isolated yield.

To better understand the unsatisfactory stereoselectivity for the atroposelective synthesis of $\mathrm{N}$-arylindoline 19 , we synthesized the corresponding $\left(\mathrm{S}_{\mathrm{a}}\right)-\mathrm{Ph}_{2}$ JoyaPhos-Pd-G3 precatalyst 21 (Scheme 5), ${ }^{[30]}$ which resembles the oxidative addition complex of the reaction in Table 1. A secondary Pd-arene interaction with the 
lower ring, which would orient the metal within the ligand sphere, was not observed. ${ }^{[31-33]}$ Instead, a rotation about the C-P bond places the coupling partners towards the outer sphere of the ligand, resulting in a buried volume of $37 \%$ and a P-Pd bond length of $2.27 \AA$. The rigidity of the ligand and the consequential repulsive interactions with bulky substrates such as 18 might hinder structural reorganizations that favor attractive non-covalent interactions. The ligand's flexibility that minimizes repulsive and maximizes attractive interactions for an optimal enantioinduction, ${ }^{[34,35]}$ is therefore strongly impacted in the case of atroposelective $\mathrm{C}-\mathrm{N}$ cross-coupling reactions, which require a high degree of substitution for sufficient configurational stability of the products.

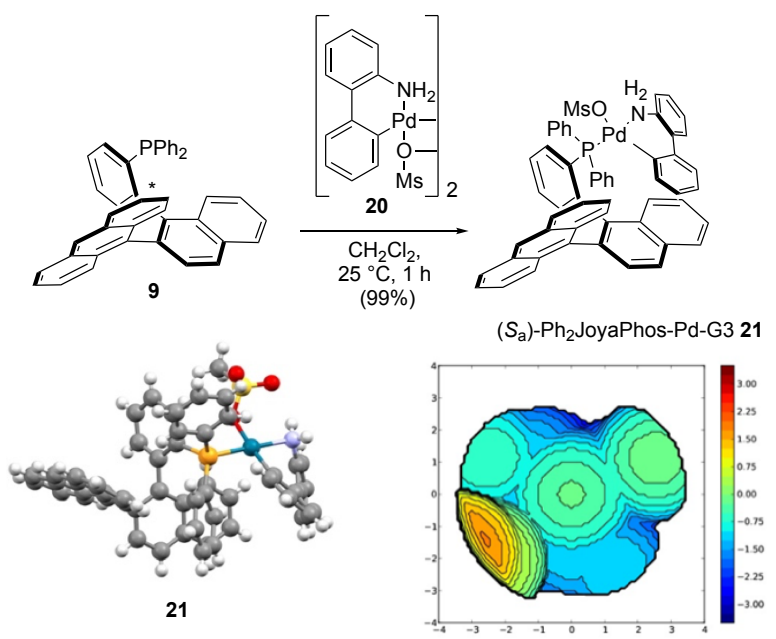

Scheme 5. Synthesis of $\left(S_{a}\right)-P h_{2}$ JoyaPhos-Pd-G3 precatalyst 21 (top), X-ray structure of $\mathbf{2 1}$ (bottom left), showing the rotation about the C-P bond and the resulting steric map with a buried volume of $37 \%$ (bottom right). ${ }^{[13]}$

A high degree of enantioinduction was accordingly observed in the benchmarking asymmetric allylic alkylation reaction (AAA) of $(E)$-1,3-diphenylallyl acetate 22 with dimethyl malonate under standard conditions (Scheme 6). ${ }^{[36]}\left(S_{\mathrm{a}}\right)$-Ph 2 JoyaPhos 8 provided the alkylation product after $1 \mathrm{~h}$ at ambient temperature in $99 \%$ yield and 95:5 e.r., while $\left(S_{\mathrm{a}}\right)-\mathrm{Cy}_{2}$ JoyaPhos 9 required $4 \mathrm{~h}$ reaction time for a comparable enantiomeric ratio of $93: 7 .{ }^{[37]}$

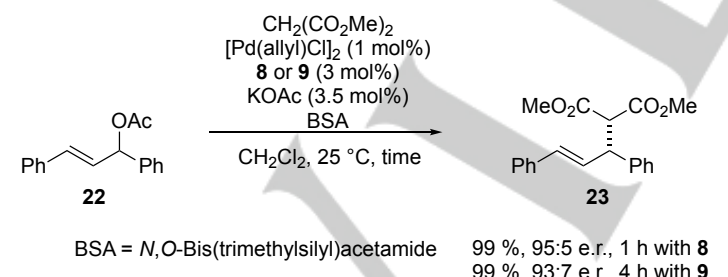

Scheme 6. Pd-catalyzed asymmetric allylic alkylation of $(E)$-1,3-diphenylallyl acetate 22 with dimethyl malonate.

\section{Conclusion}

Three topologically well-defined atropisomeric ligands were efficiently prepared in high yields and selectivity using an atroposelective aldol condensation combined with a direct esterto-antracene transformation with a suitable bifunctional organo- magnesium reagent. The ligands were structurally examined ${ }^{[38]}$ and their catalytic performance tested for two gold(I)- and two $\mathrm{Pd}(0)$-catalyzed reactions. It was observed that further extension of the ligand backbone is required for $\mathrm{Au}(\mathrm{I})$ catalysis and that high enantioselectivity is induced by the ligands in benchmarking palladium-catalyzed AAA reactions which allow the required structural arrangement of the ligands. We currently explore methods enabled by the unique structure of the atropisomeric teraryl monophosphine ligands and the modular synthesis of extended and specifically suited ligand structures using the straightforward synthetic approach presented herein.

\section{Acknowledgements}

We thank the Swiss National Science Foundation (155902 and 175746), the University of Basel, and the NCCR Molecular Systems Engineering for financial support. We also gratefully acknowledge Prof. Dr. O. Baudoin for helpful discussions, Dr. M. Neuburger and Dr. A. Prescimone for X-ray analyses and Solvias for the generous donation of ligands and phosphine chlorides.

Keywords: Atroposelective synthesis - C-N cross-coupling • Gold catalysis $\cdot$ Monophosphine ligands $\cdot$ Palladium catalysis

[1] a) G. Zuccarello, M. Zanini, A. M. Echavarren, Isr. J. Chem 2020, 60 , doi: 10.1002/ijch.201900179; b) H. Teller, S. Flügge, R. Goddard, A. Fürstner, Angew. Chem. Int. Ed. 2010, 49, 1949-1953; c) Zi, F. D. Toste, Chem. Soc. Rev. 2016, 45, 4567-4589.

[2] M. Berthod, G. Mignani, G. Woodward, M. Lemaire, Chem. Rev. 2005, 105, 1801-1836.

[3] M. M. Pereira, M. J. F. Calvete, R. M. B. Carrilho, A. R. Abreu, Chem. Soc. Rev. 2013, 42, 6990-7027.

[4] S. Akutagawa, Appl. Catal., A. 1995, 128, 171-207.

[5] B. Zilate, A. Castrogiovanni, C. Sparr, ACS Catal. 2018, 8, 2981-2988.

[6] S. Gladiali, E. Alberico, K. Junge, M. Beller, Chem. Soc. Rev. 2011, 40, 3744-3763.

[7] F. Lagasse, H. B. Kagan, Chem. Pharm. Bull. 2000, 48, 315-324

[8] H. Guo, K. Ding, L. Dai, Chin. Sci. Bull. 2004, 49, 2003-2016.

[9] J. F. Teichert, B. L. Feringa, Angew. Chem. Int. Ed. 2010, 49, 24862528 .

[10] a) A. Link, C. Sparr, Angew. Chem. Int. Ed. 2014, 53, 5458-5461; b) D. Lotter, M. Neuburger, M. Rickhaus, C. Sparr, Angew. Chem. Int. Ed. 2016, 55, 2920-2923; c) D. Lotter, A. Castrogiovanni, M. Neuburger, C. Sparr, ACS Cent. Sci. 2018, 4, 656-660.

[11] A. Link, C. Fischer, C. Sparr, Angew. Chem. Int. Ed. 2015, 54, 1216312166.

[12] T. E. Barder, S. L. Buchwald, J. Am. Chem. Soc. 2007, 129, 5096-5101.

[13] L. Falivene, Z Cao, A. Petta, L. Serra, A. Poater, R. Oliva, V. Scarano, L. Cavallo, Nat. Chem. 2019, 11, 872-879.

[14] H. Clavier, S. P. Nolan, Chem. Commun. 2010, 46, 841.

[15] A. J. Kendall, L. N. Zakharov, D. R. Tyler, Inorg. Chem. 2016, 55, 30793090.

[16] B. T. Ingoglia, C. C. Wagen, S. L. Buchwald, Tetrahedron 2019, 75, 4199-4211.

[17] A. C. Sather, H. G. Lee, V. Y. De La Rosa, Y. Yang, P. Müller, S. L. Buchwald, J. Am. Chem. Soc. 2015, 137, 13433-13438.

[18] H. Jong, S. T.-C. Eey, Y. H. Lim, S. Pandey, N. A. B. Iqbal, F. F. Yong E. G. Robins, C. W. Johannes, Adv. Synth. Catal. 2017, 359, 616-622.

[19] H. Zhang, P. Ruiz-Castillo, S. L. Buchwald, Org. Lett. 2018, 20, $1580-1583$

[20] C. Börger, A. W. Schmidt, H.-J. Knölker, Synlett 2014, 25, 1381-1384.

[21] C. Cheng, L. Pan, Y. Chen, H. Song, Y. Qin, R. Li, J. Comb. Chem. 2010, 12, 541-547.

[22] P. J. O'Connell, C. T. Harms, J. R. F. Allen, Crop Prot. 1998, 17, 207212.

[23] I. Takahashi, Y. Suzuki, O. Kitagawa, Org. Prep. Proced. Int. 2014, 46, $1-23$.

[24] O. Kitagawa, M. Yoshikawa, H. Tanabe, T. Morita, M. Takahashi, Y. Dobashi, T. Taguchi, J. Am. Chem. Soc. 2006, 128, 12923-12931.

[25] A. Nakazaki, K. Miyagawa, N. Miyata, T. Nishikawa, Eur. J. Org. Chem. 2015, 2015, 4603-4606

[26] Y. Morimoto, S. Shimizu, A. Mokuya, N. Ototake, A. Saito, O. Kitagawa, Tetrahedron 2016, 72, 5221-5229. 
[27] J. Wencel-Delord, J. Frey, A. Malekafzali, I. Delso, S. Choppin, F. Colobert, Angew. Chem. Int. Ed. 10.1002/anie.201914876.

[28] U. Christmann, R. Vilar, Angew. Chem. Int. Ed. 2005, 44, 366-374.

[29] E. R. Strieter, S. L. Buchwald, Angew. Chem. Int. Ed. 2006, 45, 925-928.

[30] N. C. Bruno, M. T. Tudge, S. L. Buchwald, Chem. Sci. 2013, 4, 916-920.

[31] J. Yin, M. P. Rainka, X.-X. Zhang, S. L. Buchwald, J. Am. Chem. Soc. 2002, 124, 1162-1163.

[32] M. Catellani, C. Mealli, E. Motti, P. Paoli, E. Perez-Carreño, P. S. Pregosin, J. Am. Chem. Soc. 2002, 124, 4336-4346.

[33] N. C. Bruno, M. T. Tudge, S. L. Buchwald, Chem. Sci. 2013, 4, 916-920.

[34] J. M. Crawford, M. S. Sigman, Synthesis 2019, 51, 1021-1036.

[35] A. J. Neel, M. J. Hilton, M. S. Sigman, F. D. Toste, Nature 2017, 543 637-646.

[36] a) B. M. Trost, D. L. Van Vranken, Chem.Rev. 1996, 96, 395-422; b) R. Prétôt, A. Pfaltz, Angew. Chem. Int. Ed. 1998, 37, 323-325.

[37] These selectivities further indicate the high enantiomeric purity of the ligands, as based on an expected linear correlation.

[38] CCDC $1989919\left(\left(S_{a}\right)-9\right), 1989920\left(\left(S_{a}\right)-21\right), 1989921 \quad(( \pm)-8)$ and $1989922\left(\left(S_{2}\right)-12\right)$ contain the supplementary crystallographic data for this paper. These data can be obtained free of charge from The Cambridge Crystallographic Data Centre. 


\section{Entry for the Table of Contents}

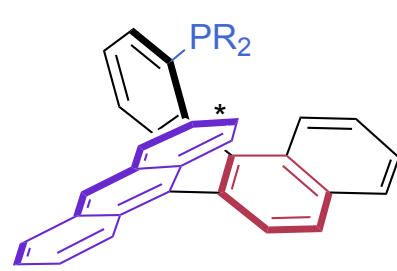

Direct

O Ester to Arene

Transformation

Stereoselective

Arene-Forming Aldol Condensation

Modular Introduction

of Dialkyl or Diaryl Phosphine

Residues

JoyaPhos: A new atropisomeric monophosphine (JoyaPhos) was prepared by the sequential de novo introduction of aromatic units, resulting in a configurationally stable teraryl structure with a well-defined topology. The ligand scaffold differs from canonical binaphthyl structures and can accommodate transition metals in a dense ligand sphere, suitable for stereoselective transformations.

Institute and/or researcher Twitter usernames: @christof_sparr 